\title{
Why Using Bed Nets is a Challenge amongst Minority Populations in Central Vietnam
}

\section{Thuan Thi Nguyen ( $\nabla$ ttnguyen@ext.itg.be )}

Instituut voor Tropische Geneeskunde https://orcid.org/0000-0002-5531-4483

\section{Xa Xuan Nguyen}

National Institute of Malaria Parasitology and Entomology

\section{Marta Wilson-Barthes}

Brown University

\section{Ikumi Sawada}

Graduate School of Biomedical Sciences

\section{Joan Muela}

University Ramon I Virgili

\section{Susanna Hausmann-Muela}

PASS International

\section{Thanh Vinh Pham}

National Institute of Malaria Parasitology and Entomology

\section{Hong Van Nguyen}

National Institute of Malaria Parasitology and Entomology

\section{Van Van Nguyen}

Centers for Disease Control

\section{Duong Thanh Tran}

National Institute of Malaria Parasitology and Entomology

\section{Umberto D'Alessandro}

Medical Research Council

\section{Koen Peeters Grietens}

Institute of Tropical Medicine: Instituut voor Tropische Geneeskunde

\section{Annette Erhart}

London School of Hygiene \& Tropical Medicine

\section{Research}

Keywords: Vietnam, forest malaria, ethnic minorities, bednet use, socio-cultural determinants, vector control strategies, mixed-methods study. 
DOl: https://doi.org/10.21203/rs.3.rs-789535/v1

License: (c) (1) This work is licensed under a Creative Commons Attribution 4.0 International License. Read Full License 


\section{Why using bed nets is a challenge amongst minority populations in Central Vietnam}

Thuan Thi Nguyen ${ }^{1,2}$, Xa Xuan Nguyen², Marta Wilson-Barthes ${ }^{3}$, Ikumi Sawada ${ }^{4}$, Joan Muela ${ }^{5,6}$, Susanna Hausmann-Muela ${ }^{6}$, Thanh Vinh Pham², Hong Van Nguyen², Van Van Nguyen ${ }^{7}$, Duong Thanh Tran², Charlotte Gryseels ${ }^{1}$, Umberto D'Alessandro ${ }^{10}$, Koen Peeters Grietens* ${ }^{1,6,8,9}$, Annette Erhart*10

* Equal contribution to last authorship

${ }^{1}$ Socio-Ecological Health Research Unit, Department of Public Health, Institute of Tropical Medicine, Antwerp, Belgium;

${ }^{2}$ National Institute of Malariology, Parasitology and Entomology, Hanoi, Vietnam;

${ }^{3}$ International Health Institute, Brown University School of Public Health, Providence, RI, United States;

${ }^{4}$ Department of Clinical Tropical Medicine, Institute of Tropical Medicine (NEKKEN), Graduate School of Biomedical Science, Nagasaki University, Nagasaki, Japan;

${ }^{5}$ University Ramon i Virgili, Tarragona, Spain;

${ }^{6}$ Partners for applied Social Sciences, PASS International, Tessenderlo, Belgium;

${ }^{7}$ Center for Disease Control, Quang Nam Province, Vietnam;

8 Amsterdam Institute for Social Science (AISSR), University of Amsterdam, Amsterdam, The Netherlands;

${ }^{9}$ School of Tropical Medicine and Global Health, Nagasaki University, Nagasaki, Japan;

${ }^{10}$ Medical Research Council Unit The Gambia at the London School of Hygiene and Tropical Medicine, Fajara, The Gambia. 


\section{Abstract}

Background: Despite free distribution of insecticidal-treated nets (ITNs) and long-lasting insecticidal nets (LLINs) to populations at-risk, malaria transmission persists in forested areas in Vietnam especially amongst ethnic minority communities. A study was conducted between April 2009 and December 2010 in four villages of Ca Dong and M'nong ethnicity located in Central Vietnam with persistent malaria transmission. The objective was to assess the feasibility of bed net use in forest settings with a specific emphasis on contrasting people's willingness/choice to use nets versus structural limitations to the uptake of the intervention.

Methods: The study used an exploratory mixed-method design for complementarity. The qualitative strand included participant observation, informal interviews, in-depth interviews, and group discussions to explore contextual barriers to bednet use. The quantitative strand consisted of a cross sectional household survey $(n=141)$ in a selected village with direct access to bed nets and the health centre. The main outcome was bednet use and related risk factors (using survey logistic regression), and secondary outcomes included the quantification of contextual factors identified during the qualitative strand.

Results: Despite self-reported bednet coverage $(72.5 \%$ of households had sufficient net coverage) and appropriate betnet use the night before the survey (82.2\% of HHMs), only $18.4 \%$ of HHMs were effectively protected by nets in both the village home and the forest field. The distribution of LLINs and ITNs was not accounted for multiple residency and sleeping places linked to slash-and-burn agriculture, and contextual factors including open-housing structured, high poverty, and animistic beliefs contributing to inappropriate use and shorter lifespan of nets. Health messages promoting bednet use were provided to the population but only $19.8 \%$ of respondents considered mosquito bites as the sole cause of malaria. The multi-variable logistic regression showed the effect of four significant factors to appropriate bednet use: being female $(A O R=8.08$; $p=0.009$ ); having knowledge of mosquito bites and malaria link ( $A O R=7.43 ; p=0.008$ ); not sleeping in the kitchen ( $A O R=24.57 ; p=0.001$ ); and, having sufficient number of bednets in the household ( $A O R=21.69$; $\mathrm{p}=0.001)$. 
Conclusion: This study identified contextual factors that constrains effective bednet use amongst ethnic minority populations living in forested areas of Central Vietnam and calls for multi-sectoral interventions to address the complexity of residual malaria transmission and reach the malaria elimination goal of 2030.

Key words: Vietnam, forest malaria, ethnic minorities, bednet use, socio-cultural determinants, vector control strategies, mixed-methods study. 


\section{Background}

Malaria control efforts in Vietnam contributed to a sharp decline of the disease burden with a decrease of over 97\% in morbidity and 99.8\% in mortality between 1992 and 2014 [1]. In the past ten years, malaria transmission has been interrupted in most of the northern and southern provinces, but persists in south-central Vietnam where several thousand cases are still annually reported [2-4]. Since 1992, and following WHO recommendations, the National Malaria Control Program (NMCP) has provided free-of-charge early detection and treatment of malaria together with integrated vector control interventions including indoor residual spraying (IRS) and insecticide treated nets (ITNs) to the population living in endemic areas [5-7]. Between 2003 and 2009 , there was a decrease in the estimated population living inmalaria endemic areas, i.e. from $23.3 \%$ $(18,563,244 / 79,668,978)$ to $17.5 \%(15,279,489 / 87,202,813)[8]$.

Universal coverage of ITNs and LLINs for populations at-risk of malaria has been repeatedly proven as a highly cost-effective public health intervention to avert malaria infections and deaths [9-15]. From 2010, Vietnam adopted a national strategy aiming for malaria elimination by 2030 , including the distribution of LLINs-, in addition to ITNs and IRS to all people at risk living in malaria-endemic areas. This strategy was funded by both national and international sources with fluctuating annual fundings $[8,16,17]$. As a result of this instable funding, the coverage of ITNs and LLINs, defined as two persons per double bedned (following the official census) distributed to all households living in high transmission areas, fluctuated between $30 \%$ of the population at risk in the early 2000s and $100 \%$ in 2010 [2,17]. Despite financial challenges, Vietnam continues to aim for universal coverage of LLINs as one of the main interventions as the country progresses toward malaria elimination. However, bednet use is not necessarily correlated with bednet coverage, and sub-optimal use of freely distributed bednets has been reported in different settings, particularly amongst ethnic minority populations $[18,19]$. Factors limiting the uptake of LLINs include users preferences and acceptability, sleeping 
places and arrangements, users perceptions of malaria risk and mosquito nuisance, insufficient coverage, and bednets design in relation to local living conditions and the cultural context [18-24].

In Vietnam, despite the overall strong decline in malaria morbidity and mortality, most of the annually reported malaria cases are concentrated in the hilly and forest fringe areas located in the south-central and central regions [2-4]. These areas are mainly inhabited by various ethnic minority groups whose exposure to and risk of malaria infections were attributed to low socio-economic- and education levels as well as their lifestyle based on forest activities and mobility [25-27]. Despite continued free bednet distribution campaigns and very high reported bednet coverage, residual hot spots of malaria transmission amongst ethnic minorities in Vietnam continue to challenge the national elimination goal. Besides the bionomics of the local malaria vector Anopheles dirus- whose exophagy and exophilie has been shown to challenge the efficacy of ITNs and LLINs [28], various studies have shown that the use of bednet by local populations most at risk was varied and inconsistent by housing style, place and time representing a knowledge gap for the NMPC $[26,29,30]$.

This paper reports the results of a mixed-method study assessing local factors limiting the uptake of bednets amongst ethnic minority groups living in a remote forested area of central Vietnam. This study was embedded in a larger community-based cohort study on the epidemiology of Plasmodium vivax [31,32]. 


\section{Methods}

\section{Study site and population}

The study was conducted from April 2009 to January 2011 in four villages of Tra Leng and Tra Don communes in Nam Tra My district of Quang Nam province. The total population consisted of 1,810 individuals (352 households) during the 2009 census [31]. It was found from the larger study that a majority of the local population was of M'nong and Ca Dong ethnicity who practiced slash-and-burn agriculture and cultivated cinnamon plantations. M'nong and Ca Dong households lived in households made of wooden planks, featuring gaps between planks, walls, and roofs. Malaria transmission was perennial in the study area with two peaks in May-June and October-November. The main malaria vector in this area, Anopheles dirus, is highly anthropophilic, displaying early evening and outdoor biting behaviour [28,33]. In April 2009, malaria prevalence was determined at $7.8 \%$ with a predominance of P.falciparum infections (81.4\%) by light microscopy, while by molecular techniques (PCR) the prevalence was three times higher (22.6\%) with a higher proportion (43.2\%) of P.vivax [31].

\section{Study design}

The study used an two-stage exploratory mixed-method design (in standard annotation: [QUAL $\rightarrow$ QUAN]) [34]. The qualitative (QUAL) strand used an ethnographic approach for data collection to gain an in-depth understanding of the local context and barriers to effective bednet use. Preliminary findings from the qualitative strand were used to inform the design and development of a structured questionnaire in the quantitative (QUAN) strand, consisting of a household survey to validate and triangulate previous findings [35].

\section{Qualitative strand}

Data collection. Qualitative data were collected in the four study villages during three periods of field work between April 2009 and January 2011. Data were collected in both rainy and dry season through participant 
observation (PO), informal interviews (IIs), in-depth interviews (IDIs), and informal group discussions (IGDs). During PO, researchers observed everyday activities and how people used their bednet in different locations and at different times. Ils were conducted as part of spontaneous conversations with local people, sometimes combined with POs, and often led to follow-up IDIs. Once trust was built with the participants, and response bias due to social desirability was minimized, the researchers proceeded to organize IDIs with participants to discuss specific topics, including sensitive questions concerning bednets received from the NMCP. Conversations were conducted in Vietnamese and local languages with the help of a translator when needed. Interviews were recorded, transcribed, and translated into English. Informal rather than formal interviews and discussions were preferred as formality exacerbated social hierarchies between participants of Kinh, M'nong, and Ca Dong ethnicities, and socially desirable responses by the participants.

Sampling. Participants were theoretically sampled using emergent theory [36]. Participants were selected based on criteria such as residence, access to health services, ethnicity, occupation, gender, bednet, health service use and knowledge of malaria transmission and control measures. Sampling aimed at maximizing variability amongst residents including men, women, young adults and elderly people. Additionally targeted profiles of participants were slash-and-burn farmers, malaria patients, school children, teachers, health professionals, and representatives of the local authority.

Data analysis. Data analysis was concurrent with data collection following a continuous and iterative process until reaching saturation when no new information was emerging from collected data. Data were coded and grouped following common themes. Preliminary results were used to adapt and expand guidelines for interviews, discussions, and observations which served to confirm, refute, or complement preliminary results. Data coding and analysis were performed using NVivo 10 Qualitative Analysis software (QSR International Pry Ltd. Cardigan UK). 


\section{Quantitative strand}

Data collection. Quantitative data were collected from October to December 2010. A structured questionnaire in both English and Vietnamese language was developed using preliminary qualitative results. The paper-based questionnaire consisted of household-level and individual-level questions. The household-level questions were asked to household leaders (HHLs) to quantify bednet ownership, mobility patterns, and sleeping places within the household. The individual-level questions were asked to household members (HHMs) to measure individual knowledge of malaria, exposure to the vector, and bednet use. Data were collected by field workers who were local health workers, and staff from the National Institute of Malariology, Parasitology, and Entomology (NIMPE) in Hanoi. During home visits to administer the survey questionnaire, in addition to asking survey questions on bednet use/status, field workers directly observed the presence and status of bednets at the respondent's home to validate the respondent's responses.

Sampling. Village 1 was selected for the survey as it had the highest number of vivax malaria cases in the main cohort study in 2009 [32]. The sampling frame consisted of households registered in the 2009 census, who were all invited to answer the questionnaire. HHLs were those identified by the census, while HHMs were family members (adults and children) who self-reported that they had had malaria prior to the survey. Adults were defined as participants who were 16 year-old or older at the time of the survey, and children were participants under 16 year-old. Field workers visited households with absent dwellers up to four times to reduce the non participation rate.

Data analysis. Data were entered using Epi-Info 6.04 and analysed using Stata 12.0 (Stata Corporation, College Station, Texas, USA). Summary statistics were done using Chi-square- or Fisher's exact tests for differences between categorical variables while Wilcoxon rank-sum tests were used to compare continuous (non-normally 
distributed) variables (significant $\mathrm{p}<0.05$ ). The survey design was taken into account using the "svy" command in Stata with household as the primary sampling unit. The socio-economic status (SES) of households was categorized as lowest-, low-, and higher SES according to their livestock ownership as defined elsewhere [31]. Bednet status was assessed, with nets that had large tears allowing insects to enter being categorized as "broken"; those without tears were categorized as "intact". Bednet use was calculated at individual level $(n=141)$ using the self-reported bednet use the night before the survey. Additionally, protection by bednet was estimated for each participant based on the following indicators: frequency of use, sleeping places, multiple residences (i.e, village home and the field plot huts), the presence of a bednet at the plothut, and bednet hanging practices. Participants who stated they "always" slept under a hung-up bednet at both their village home and their plot huts, and those who slept under a hung-up bednet at the village home and did not have a plot hut, were categorized as "effectively protected" by bednet. The category of "unprotected" by bednet included particpants who reported that they inconsistently slept under a hung bednet at their village home, and/or at their fields. A multi-variable analysis using survey logistic regression was conducted to determine the effect of independent risk factors (gender, education, occupation, knowledge of malaria, sufficient coverage of bednet and blanket, and sleeping places) on appropriate bednet use defined as sleeping under a hung bednet the night before the survey.

\section{Ethical considerations}

This study was approved by the Ethical Committee of NIMPE in Hanoi, Vietnam (approval decision 362/QHQT), and the Institutional Review Board of the Institute of Tropical Medicine in Antwerp, Belgium (IRB/AB/dvm/183). All fieldwork in the qualitative strand followed the Code of Ethics of the American Anthropological Association (AAA) [37]. Village leaders from both ethic groups and representatives of the Commune People's Committee provided their consensus after having been informed on the study objectives and procedures. The QUAL strand used oral informed consent in which the participants agreed to take part in 
the study after receiving explaination by the researcher about the study objectives, and the participant's rights to answer or not any questions as well as to terminate the interview or discussion at anytime as the participant wished to. The choice of oral consent was made in the consideration of high illiteracy amongst the study populations, and the cultural sensitiveness of the topic, e.g. people's sleeping places, and whether they used the bednet given by the government. The researcher treated QUAL data with the highest confidentiality, and stored data in password-protected devices. All participants in the QUAN strand were asked to consent before inviting to answer the survey questionnaire. When the participant was under 16 year-old, their parents or guardian were asked to consent on their behalf. All participants were informed of the intended use of the results for scientific publication, and their responses were anynomized as to protect their access to, and use of public health service. 


\section{Results}

\section{Study participants}

The QUAL strand included 20 semi-structured interviews and three group discussions. Selected participants were male and female of different age groups and different professions such as farmers, plantation workers, students, teachers, health workers, local authorities and leaders. The QUAN strand included 80 HHLs (adults) and related $61 \mathrm{HHMs}$ (15 adults and 46 children). The number of participated household accounted for $98.8 \%$ $(80 / 81)$ of all households living in village 1 . Of the study sample $(n=141), 74$ participants $(52.5 \%)$ were female and $67(47.5 \%)$ were male. Participant's age ranged from 1 to 88 years with the median age of 7 years [IQR: 310] amongst children, and of 27 years [IQR: 22-38] amongst adults. The vast majority of households (77.5\%, $62 / 80)$ belonged to the lowest SES while the rest $(22.5 \%, 18 / 80)$ belonged to the low SES category. All but one of the 80 households belonged to the M'nong- while only one was from the Ca Dong ethnicity.

\section{ITN/LLIN coverage and use}

Prior to 2009, the study population had received some ITNs from the NMCP but the majority (76.5\%) of the households had no bednets [31]. In 2010, the NMCP distributed LLINs for double beds, i.e. one bednet for two adults. At the time of the survey, housholds had both ITNs and LLINs (thereafter referred to as the "bednet" when mentioned in general) at home. Of the 80 households, 59 (72.5\%) had adequate bednet coverage, i.e. at least one bednet for a maximum of two people. However, only $24.3 \%(19 / 78)$ of households owned bednets that were still intact, and up to $33.3 \%$ had exclusively broken bednets (Table 1 ).

Of 141 survey participants, $82.2 \%$ reported having used a bednet the night before the survey. However, only $7.8 \%(9 / 116)$ of participants said they actually slept under a hung bednet, while the majority $(92.2 \%, 107 / 116)$ used their bednet as a blanket (Table 1). Further analysis of bednet use to estimate effective protection (Figure 1) found that only $28.4 \%$ (40/141) were considered as fully protected by the net at home (in the village). The main reason was due to sleeping near the fire in the kitchen for warmth and believing in the repellent effect of smoke. However, after accounting for those who slept at the plot hut without having or hanging a net, only $6.3 \%(9 / 141)$ were protected by bednets both at home and plot hut. Considering $12.1 \%(17 / 141)$ of participants were protected at home and did not have a plot hut, a total of $18.4 \%(26 / 141)$ of all survey participants were assumed to be fully protected.

\section{Factors associated with inappropriate bednet use}


Working practices and multiple residences. Ca Dong and M'nong households traditionally moved within the forest to cultivate following rotational slash-and-burn farming. The government legitimized its role in forest management through reinforcing a national law on forest protection in 1991 and 2004 that prohibited slashand-burn practices and hunting amongst other forest exploitation activities [38,39]. Under these changes, from 2003 onwards, the provincial authority established the commune of Tra Leng and its administrative area with identified geographic boundaries for residential, fixed farmland agriculture (e.g. for cassava and rice) near the newly established residential areas, built hydro power plants, protected part of the surrounding forest, and destined other parts to the production of cinnamon and pepper plantations. Ca Dong and M'nong households were resettled to the newly-built village houses in the residential areas and cultivated cinnamon and/or rice at their forest fields located in the converted forest area.

Our survey (Table 2) showed that the vast majority of household owned forest fields and the average time to commute on foot between the village and the forest field was more than one hour. Most households (71.2\%, 57/80) said that they had a plot hut in their forest fields. The QUAL strand showed that households divided their time between the village home and the forest field, with children usually staying in the village to attend school, and adults staying in the forest field for farming. The median duration of stay at the fields was 19 days, and in a range from 2 to 56 days (Table 2). The majority $(54.3 \%, 31 / 57)$ of HHLs said they did not bring any of their bednets to the plot hut. A common reason was having insufficient number of bednets to cover for the entire household in both locations and therefore intact bednets were often left at home for children to use, and the broken ones, if any, would be kept at the plot hut. Additional reasons for not bringing bednets to the fields included: (1) short durations in the forest field that did not warrant bringing bednets; (2) not having sufficient space inside the plot hut to hang a bednet; and, (3) the reticence to get bednets dirty or torn. Specific households members, mostly male adults stayed overnight in the forest for logging and hunting, also exposed themselves to malaria. Stays in the deep forest usually lasted several days and bednets were rarely brought because of the hardship endured while moving around in the forest (a need to travel "light"), and the difficulty of finding a suitable spot in the forest to hang a bednet.

Sleeping places. Sleeping around the kitchen fire was common practice in the area which was due to the cold and humid climate as well as animistic beliefs. Bednets were rarely hung there due to fire hazards and a lack of space to properly hang a bednet. Indeed partially burnt LLINs and ITNs were sometimes observed. Up to $60.0 \%(48 / 80)$ of HHLs answered that their family members, predominantly elders, often slept around the kitchen fire (Table 1$)$. The majority $(75.0 \%, 60 / 80)$ of HHLs believed that smoke in their kitchen repelled small 
insects including mosquitoes, and sleeping under a hung bednets in the kitchen at night was therefore unnecessary (Table 1).

Housing conditions. Extracted data from the cohort showed that houses in the village were made of temporary materials including wooden walls (100\%) and tin roofs $(93.7 \%)$. The house structures were open with gaps between wooden planks, and between the walls and the roofs allowing mosquitoes to easily enter and exit. Due to these open structures, houses were quite cold and humid at night, particularly in the rainy/malaria season. Participants explained that due to poverty they could not afford buying sufficient blankets to keep warm at night. In the survey, 74.7\% (59/78) of HHLs reported using their broken bednet either as pillows $(49.1 \%, 29 / 59)$ or blankets $(33.8 \%, 20 / 59)$ (Table 1$)$.

Bednet lifespan. The qualitative strand identified several reasons for LLINs to be torn after a short period of use. Participants explained that the netting of LLINs was too hard, and easily broken when people removed the bednet from the wooden walls or on the bamboo floors, or when children played inside the house. The open housing structure allowed animals, particularly chickens, to enter the house, and they also caused damage and holes in the nets. The house structure also exposed bednets to soil and dirt, and together with children urine and faeces (households could rarely afford buying diapers), these factors contributed to more frequent bednet washing. 35.9\% (28/78) of HHLs responded in the survey that they washed their bednets every week (Table 1). Frequent bednet washing and hanging them outdoors to air-dry with animals and children playing caused additional damage and further shortened LLINs life-span. Broken LLINs were not repaired or mended because patched bednets were considered a visible sign of poverty. Additionally, broken LLINs were not worth repairing as the hard netting caused skin irritation and were useful for alternative purposes other than sleeping (Images 1a-f).

Malaria knowledge. Local malaria control program provided the population with health messages through printed materials and public campaigns focusing on the benefits of using bednet for malaria protection. The qualitative strand found that the aetiology of febrile illness, including malaria, was frequently linked to ancestor worship or natural events. This was confirmed in the survey where $43.3 \%(61 / 141)$ of respondents identifying that malaria was caused by mosquito bites. Other non-mutually exclusive aetiologies for malaria included the hot sun (52.4\%, 74/141), hard work (48.9\%, 69/141), and drinking bad water (41.1\%, 58/141) (Table 3). Only about one in five participants $(19.8 \%, 28 / 141)$ considered mosquito bites as the sole cause of malaria. Of participants who said they "always" or "sometimes" slept under a bednet, $60.3 \%(73 / 121)$ stated to do so to protect themselves against malaria (Table 1). 
Table 4 summarizes the multi-variable analysis for appropriate bednet use, measured through self-reported bednet use the night before the survey using a hanging net. Significant potential risk factors identified by the univariate analysis were sex, education, occupation, coverage of bednet, coverage of blankets, knowledge of the mosquito-malaria link, not sleeping in the kitchen, and not sleeping under a blanket the night before the survey. The multivariate adjusted analysis showed that four factors were independently associated with appropriate bednet use. More specifically, female participants were 8 times more likely than male (AOR=8.08; $\mathrm{p}=0.009$ ) to always sleep under a hung-up bednet, and so did participants who acknowledged the mosquitomalaria link ( $A O R=7.43 ; p=0.008)$. Participants living in a house with sufficient coverage of bednets $(A O R=21.69 ; p=0.001)$ and those not sleeping in the kitchen ( $A O R=24.57 ; p=0.001)$ the night before the survey, were also significantly more likely to appropriately use bednets. Despite large $95 \% \mathrm{Cls}$ around the AORs due to the small sample size, the effects were found highly significant. 


\section{Discussion}

This mixed-method study assessed factors influencing the use of bednets amongst the Ca Dong and M'nong ethnicities living in Tra Leng and Tra Don Commune in Nam Tra My District of Quang Nam province. The latter have been summarized in the theoretical model proposed in Figure 2 and can be categorized under (1) working conditions, (2) housing and living conditions, (3) perception of bednets and their protective effect, and (4) perceived malaria etiology and severity. The model provides insights into the effect of each factor on the effective use of bednets (estimated $<20 \%$ ) in the face of the universal coverage reported by the NMCP $(100 \%)$ and proposes respective solutions.

Despite relatively high bednet coverage in village houses, and high self-reported bednet use the night before the survey, the actual expected protection offered by a bed net sharply declined when the concept of bed net protection was changed from a single standardized question to being measured as a fully operationalized concept based on prior qualitative results. This indicates that measuring the extent to which people are effectively protected from biting vectors while sleeping at night and in (all) places where they are is far from straightforward as reported elsewhere [40-42]. The relevant factors to measure protection were only clear after ethnographic research and were a combination of individual- and household based factors, i.e, amount and intactness of available bednets in the household, frequency- and pattern of use (hung-up or use as blanket), sleeping practices (e.g. sleeping in the kitchen) and places (double residency). Consequently, less than a fifth of the study population were estimated as fully protected by bednets at night at both village homes and/orforest fields. In the study context, the local populations practiced sleeping at the plot hut as a necessity for slash-and-burn farming, thus, accounting for factors influencing proper and consistent bednet use increases the internal validity of data collection tool. In other study settings in Vietnam and South-East Asian countries where local populations also practice mobility and multiple residency system, existing researches also reported to use similar operationalization taking into consideration of not only sufficient bednet coverage and self-reported use but also intactness, prequency and correct use, and sleeping places (whether in the forest, the farm or plot hut or the official village) $[26,29,40,43,44]$. For Vietnam and other South-East Asian countries with similar problem of residual malaria transmission amongst ethnic minority populations, many of whom farming in the forest is part of their economic strategy, the operationalization and measurement of bednet use as a concept from these studies offer greater external validity and can be used by the NMCPs to precisely estimate the protection of bednets as well as to effectively inform the vector control strategy. Therefore, going forward malaria surveys should avoid assessing effective bednet use with a single question 
("did you use a bednet last night") and instead include an exploratory qualitative phase to identify contextual factors and use these results to inform the development of a standardized survey questionnaire.

Secondly, this study shows how indigeneous populations practicing slash-and-burn farming and other forestbased activities for variable duration of time, do not meet the assumption that each household has a single fixed sleeping place. This has also been shown in other minority contexts in Vietnam and Cambodia $[26,29,40]$. The NMCP bednet distribution campaigns are done on the basis of one double LLIN to every two persons in the household, while a majority of Ca Dong and M'nong households lived in both village houses and the plot huts. In those cases where specific household members sleep at the field while others sleep in village houses, the existing assumption of universal coverage (i.e. "two persons per net") does no longer apply and inevitably results in low effective coverage. Extra single LLINs (in addition to the current "two persons per double net") and other tools such long-lasting insecticidal hammock nets (LLHNs) for local populations working in forest fields or engaging in other forest-based activities can provide extra protection [30,45-47]. These additional tools are relevant not only to ethnic minorities in Central Vietnam but to many other South-East Asian countries where forest malaria occurs [48-51].

An important cultural factor that emerged from the QUAL strand was the local habit to sleep around the fire both for spiritual and practical reason (feeling cold), was found as a major risk factor for inappropriate use of bednet as shown in the multivariable analysis. Indeed participants who didn't sleep in the kitchen the night before the survey were 25 times more likely to have appropriately used a bednet. The second most important risk factor for appropriate use of bednet was the sufficient coverage as estimated by the respondent $(A O R=21.8)$. Despite the lack of precision around this estimate it was found highly significant. Women and respondents who know the link between malaria and mosquito bites were also more likely to appropriately use bednets. In addition, our study also showed that poor housing (open wooden houses) and living conditions influenced the way local people used and maintained their nets and consequently their expected protective effect. The effect of improved housing conditions on malaria exposure has been repeated shown in different endemic settings [52-55]. For populations such as Ca Dong and M'nong who live near or inside the forest, adapted housing materials and improved housing structure to reduce malaria transmission represents an additional solution.

These findings are relevant to the current NMCP in Vietnam as the coutry continues to strictly adhere to the global strategy on maintaining universal coverage of LLINs, i.e. in 2018, more than 324,000 LLINs and ITN were 
distributed to the population living in high endemic areas [56]. Ethnic minority populations including those in this study were reported to have low use of LLINs and LLHNs when sleeping at plot huts or the forest fields where the risk is higher than the village houses [29] [57]. This implies that for effective effect of bednets, consistent and appropriate use of nets should be practiced by these minority populuations at all sleeping locations. For the NMCP, there are windows of opportunity to achieve more effective vector control by provoding sufficient coverage of LLINs and LLHNs to the populations for use in all sleeping locations. In addition, the distribution of these tools should be accompanied by a tailored communication campaign with communities to explain about malaria risk and how to proporely use LLINs and/or LLHNs in culturally sensitive manner.

This study calls for using relevant methods to communicate to and work with communities to make LLINs as well as personal protective tools in malaria control meet the expectations and preferences of the population and to assure a better understanding of health messages. Malaria messages provided by the NMCP to ethnic minority population are in Vietnamese language, and focus on malaria risk (defined as sleeping at the forest field and going to the forest) and behavior change (sleeping under a LLIN). For effective communication, these messages should be made in local languages, and be sensitive to the existing stereotypes of ethnic minorities as being "backward" and "primitive" [58,59]. In addition, for LLIN and other personal protective tools to be used effectively by local populations, the product design should include features (i.e. netting materials, bednet size, colour, etc.), that are practical, and preferred by the populations. Products need to take into consideration of very different conditions of sleeping places in the administrative village, the plot hut, and the forest.

Lastly, this study calls for using interdisciplary and multisectoral approaches to vector control and malaria elimination strategies in South East Asia, including Vietnam. This region continues to prioritize vector control interventions, and appropriate LLIN use still provides substantial protection for subgroups in the populations who have earlier sleeping time and fewer outdoor activities in the evening (when the dominant vectors are presumed or shown to be active) $[30,40,57,60]$. However, to address the complexity in vector behavior and behavior of local populations, particularly male adults who have high risk due to activities outdoors and in the forest [57,60-62], novel vector control tools (insecticide treated hammocks, blankets, cloths etc.) that are effective to prevent mosquito bites in both indoors and outdoors, as well as pratical and useful to the populations, are needed. Mixed-methods study designs and formative research approaches that include iterative processes for design, implementation and continuously adapting and monitoring the implementation, 
offer methodological strength, and relevance to solving the problem in the uptake of vector control in specific contexts, and the effectiveness of malaria elimination strategies in general.

The main limitation of the this study is the time (10 years) between the collection and the publication of these data. We believe the data we report here are not outdated because more recent observations in similar ethnic minorities in south-central Vietnam (Thuan Thi Nguyen, unpublished) find that low LLIN and LLHN use is related to farmers living in both the village and the forest field, are still a bottleneck for malaria control. The second limitation was due to limited funding which resulted in having a small QUAN sample size, with participants living in closer proximity to the local commune health center who have better access to health information than people living in further away villages. If a larger sampling was included, we would expect lower results of the protection of bednets and knowledge of malaria as people living in other village might have less access to information and health service for malaria due to difficult geographic access, likely higher poverty and possibly longer stays in the forest field for slash-and-burn farming. Despite these limitations, the study findings are still relevant for malaria control and elimination strategies in Vietnam where transmission continues to occur in the forest fringes amongst ethnic minority groups whose mobility patterns, multiple residency, and poverty limit the effectiveness of standard vector control tools $[26,43,62,63]$.

\section{Conclusions}

Our mixed methods approach allowed for an indepth understanding of the different challenges to appropriately use bednets amongst imporished minority populations living in forested areas in Central Vietnam. Our theoretical model proposes several windows of opportunity to further improve the effective use of existing LLINs by increasing their current coverage above $100 \%$ and by developing a multi-disciplinary and multi-sectorial approach to develop new contextualized tools that will meet the requirements of the real living and working conditions of local populations. 


\section{Competing interests}

The authors declare that they have no competing interests.

\section{Funding}

The study was funded by the UBS Optimus Foundation and the Framework Agreement Project (FA3) of the Belgium Cooperation Development. NTT is funded with a PhD scholarship by the Belgian Directorate of Development Cooperation (DGD).

\section{Authors' contributions}

KPG and XXN conceived the study. KPG, NXX, JMR and SHM performed the anthropological fieldwork. NVV and TTD facilitated the fieldwork. NXX, KPG and NTT analysed the qualitative data. The quantitative anthropological data were analysed by NTT, IS, MWB and with additional analysis and reviews by EA. NTT, KPG and MWB wrote the manuscript. XXN, DTT, TVP, HVN, VVN contributed further inputs to the manuscript. CG, EA, UDA, JM, KPG reviewed and edited the manuscript. Both EA and KPG shared the role of senior and co-last authors in this article. All authors read and approved the final manuscript.

\section{Ethics approval and consent to participate}

This study was approved by the Ethical Committee of NIMPE in Hanoi, Vietnam (approval decision 362/QHQT), and the Institutional Review Board of the Institute of Tropical Medicine in Antwerp, Belgium (IRB/AB/dvm/183). Informed consent was obtained from all from the study participants or the legal guardian of patients who were under 18 years of age.

\section{Consent for publication}

All authors provided their consent for the publication of this manuscript.

\section{Availability of data and materials}

The authors confirm that the data supporting the findings of this study are available within the article and its Supplementary Materials.

\section{Acknowledgements}

We would like to thank the communities of Ca Dong and M'nong who contributed their time and efforts to take part in this study. We would also like to acknowledge the invaluable support to our fieldwork by Mr. Viet, the former Chairman of Tra Leng Commune, whose life was taken away by the tragic land slides in Tra Leng in 2020. Special 
thanks to Yoriko Masunaga and Brecht Ingelbeen for their help with an additional review of the manuscript and lostin-translation.be for the English text editing. 


\section{References}

1. Goldlust SM, Thuan PD, Giang DDH, Thang ND, Thwaites GE, Farrar J, et al. The decline of malaria in Vietnam, 1991-2014. Malar J [Internet]. BioMed Central; 2018 [cited 2020 May 4];17:1-12. Available from: https://malariajournal.biomedcentral.com/articles/10.1186/s12936-018-2372-8

2. NIMPE. Malaria epidemiological stratification in Vietnam 2014 (Internal Report). Hanoi, Vietnam; 2014. 3. Wangdi K, Canavati SE, Ngo TD, Tran LK, Nguyen TM, Tran DT, et al. Analysis of clinical malaria disease patterns and trends in Vietnam 2009-2015 11 Medical and Health Sciences 1117 Public Health and Health Services. Malar J. BioMed Central Ltd.; 2018;17:1-15.

4. NIMPE. Malaria Epidemiological Stratification in 2019 (Internal Report). Hanoi, Vietnam; 2019.

5. Hung LQN, De Vries PJ, Giao PT, Nam N V., Binh TQ, Chong MT, et al. Control of malaria: A successful experience from Viet Nam. Bull World Health Organ. World Health Organization; 2002;80:660-6.

6. Barat LM. Four malaria success stories: How malaria burden was successfully reduced in Brazil, Eritrea, India, and Vietnam. Am J Trop Med Hyg. The American Society of Tropical Medicine and Hygiene;

2006;74:12-6.

7. Schuftan C. A story to be shared: the successful fight against malaria in Vietnam. Toxicol Sci [Internet]. 2000 [cited 2020 Jun 10];137. Available from: http://www.afronets.org/files/malaria.pdf

8. Vietnam MOH. National Strategy for malaria control and elimination in the period 2011-2020 and orientation to 2030 [Internet]. Hanoi. 2011. Available from:

https://www.apmen.org/sites/default/files/all_resources/Vietnam National Strategy for Malaria control _ Elimination 2011-2020.pdf

9. D'Alessandro U, Olaleye B, Langerock P, Aikins MK, Thomson MC, Cham MK, et al. Mortality and morbidity from malaria in Gambian children after introduction of an impregnated bednet programme. Lancet. Elsevier; 1995;345:479-83.

10. D'Alessandro U, Olaleye BO, McGuire W, Thomson MC, Langerock P, Bennett S, et al. A comparison of the efficacy of insecticide-treated and untreated bed nets in preventing malaria in Gambian children. Trans $\mathrm{R}$ Soc Trop Med Hyg [Internet]. Oxford Academic; 1995 [cited 2020 Dec 4];89:596-8. Available from:

https://academic.oup.com/trstmh/article-lookup/doi/10.1016/0035-9203(95)90401-8

11. Yukich JO, Lengeler C, Tediosi F, Brown N, Mulligan JA, Chavasse D, et al. Costs and consequences of large-scale vector control for malaria. Malar J. 2008;7:1-12.

12. White MT, Conteh L, Cibulskis R, Ghani AC. Costs and cost-effectiveness of malaria control interventions A systematic review. Malar J. 2011;10:1-14.

13. Murphy C, Ringheim K, Woldehanna S, Volmink J. Reducing malaria's burden: evidence of effectiveness for decision makers (Technical Report), Global Health Council. Washington DC, USA; 2003.

14. WHO. Insecticide-treated mosquito nets: a WHO position statement [Internet]. 2007 [cited 2020 Dec 2]. Available from:

https://www.earth.columbia.edu/sitefiles/file/bednets/WHO_global_malaria_programme_LLIN_aWHO_posi tion_statement.pdf

15. Pluess B, Fc T, Lengeler C, BI S. Indoor residual spraying for preventing malaria (Review). Cochrane Rev. 2010;

16. Vietnam MOH. Vietnam National Action Plan for Malaria Control from 2015 to 2020 (Internal Publication). Hanoi, Vietnam; 2014.

17. WHO. Malaria Country Profile Vietnam: 2017 [Internet]. 2018 [cited 2020 Jun 10]. Available from: https://www.who.int/malaria/publications/country-profiles/profile_vnm_en.pdf

18. Peeters Grietens K, Xuan XN, Van Bortel W, Duc TN, Ribera JM, Ba Nhat T, et al. Low perception of malaria risk among the Ra-glai ethnic minority in south-central Vietnam: Implications for forest malaria control. Malar J. BioMed Central; 2010;9:23.

19. Grietens KP, Muela Ribera J, Soto V, Tenorio A, Hoibak S, Aguirre AR, et al. Traditional nets interfere with the uptake of long-lasting insecticidal nets in the Peruvian Amazon: The relevance of net preference for 
achieving high coverage and use. PLoS One. Public Library of Science; 2013;8.

20. Aikins MK, Pickering H, Alonso PL, D’Alessandro U, Lindsay SW, Todd J, et al. A malaria control trial using insecticide-treated bed nets and targeted chemoprophylaxis in a rural area of The Gambia, West Africa. Trans R Soc Trop Med Hyg [Internet]. Oxford Academic; 1993 [cited 2020 Jun 10];87:25-30. Available from: https://academic.oup.com/trstmh/article-lookup/doi/10.1016/0035-9203(93)90172-M

21. Dye TD, Apondi R, Lugada ES, Kahn JG, Smith J, Othoro C. 'Before we used to get sick all the time': Perceptions of malaria and use of long-lasting insecticide-treated bed nets (LLINs) in a rural Kenyan community. Malar J [Internet]. BioMed Central; 2010 [cited 2020 Jun 10];9:345. Available from: https://malariajournal.biomedcentral.com/articles/10.1186/1475-2875-9-345

22. Singh M, Brown G, Rogerson SJ. Ownership and use of insecticide-treated nets during pregnancy in subSaharan Africa: A review. Malar. J. BioMed Central; 2013. p. 1-10.

23. Lindsay SW, Jawara M, Paine K, Pinder M, Walraven GEL, Emerson PM. Changes in house design reduce exposure to malaria mosquitoes. Trop Med Int Heal. John Wiley \& Sons, Ltd; 2003;8:512-7.

24. Lover A, Sutton B, Asy A, Wilder-Smith A. An exploratory study of treated-bed nets in Timor-Leste: Patterns of intended and alternative usage. Malar J [Internet]. BioMed Central; 2011 [cited 2020 Jun 10];10:199. Available from: https://malariajournal.biomedcentral.com/articles/10.1186/1475-2875-10-199 25. Thang ND, Erhart A, Speybroeck N, Hung LX, Thuan LK, Hung CT, et al. Malaria in central Vietnam: Analysis of risk factors by multivariate analysis and classification tree models. Malar J. BioMed Central; 2008;7:1-9.

26. Gryseels C, Grietens KP, Dierickx S, Bannister-Tyrrell M, Trienekens S, Xuan XN, et al. High mobility and low use of malaria preventive measures among the jarai male youth along the Cambodia-Vietnam border. Am J Trop Med Hyg. American Society of Tropical Medicine and Hygiene; 2015;93:810-8.

27. Erhart A, Thang ND, Hung NQ, Toi L V., Hung LX, Tuy TQ, et al. Forest malaria in Vietnam: A challenge for control. Am J Trop Med Hyg [Internet]. 2004 [cited 2020 Oct 28];70:110-8. Available from:

https://www.ajtmh.org/content/journals/10.4269/ajtmh.2004.70.110

28. Van Bortel W, Trung HD, Hoi LX, Van Ham N, Van Chut N, Luu ND, et al. Malaria transmission and vector behaviour in a forested malaria focus in central Vietnam and the implications for vector control. Malar J [Internet]. BioMed Central; 2010 [cited 2020 Jun 10];9:373. Available from:

https://malariajournal.biomedcentral.com/articles/10.1186/1475-2875-9-373

29. Peeters Grietens K, Nguyen Xuan X, Van Bortel W, Ngo Duc T, Muela Ribera J, Ba Nhat T, et al. Low perception of malaria risk among the Ra-glai ethnic minority in south-central Vietnam: implications for forest malaria control. 2005; Available from: http://www.malariajournal.com/content/9/1/23

30. Grietens KP, Xuan XN, Ribera JM, Duc TN, van Bortel W, Ba NT, et al. Social determinants of long lasting insecticidal hammock-use among the Ra-Glai ethnic minority in vietnam: Implications for forest malaria control. PLoS One. Public Library of Science; 2012;7.

31. Thanh PV, Van Hong N, Van Van N, Van Malderen C, Obsomer V, Rosanas-Urgell A, et al. Epidemiology of forest malaria in Central vietnam: The hidden parasite reservoir. Malar J [Internet]. BioMed Central Ltd.; 2015 [cited 2020 Jun 10];14:86. Available from:

https://malariajournal.biomedcentral.com/articles/10.1186/s12936-015-0601-y

32. Pham TV, Nguyen H Van, Aguirre AR, Nguyen V Van, Cleves MA, Nguyen XX, et al. Plasmodium vivax morbidity after radical cure: A cohort study in Central Vietnam. PLoS Med. Public Library of Science; 2019;16:e1002784.

33. Garros C, Van Nguyen C, Trung HD, Van Bortel W, Coosemans M, Manguin S. Distribution of Anopheles in Vietnam, with particular attention to malaria vectors of the Anopheles minimus complex. Malar J. BioMed Central; 2008;7:1-9.

34. Creswell JW, Clark VLP. Designing and Conducting Mixed Methods Research. Sage Publ Inc. Third Edit. London: SAGE Publications Inc.; 2018. p. 144-54.

35. Seale C. Quality Issues in Qualitative Inquiry. Qual Soc Work Res Pract [Internet]. Sage PublicationsSage 
CA: Thousand Oaks, CA; 2002 [cited 2020 Jun 10];1:97-110. Available from:

http://journals.sagepub.com/doi/10.1177/147332500200100107

36. Hodgson GM. The Concept of Emergence in Social Sciences: Its History and Importance. Emergence. 2000;2:65-77.

37. American Anthropological Association. Code of Ethics of the American Anthropological Association [Internet]. AAA Statement Ethics. 2012 [cited 2020 Jun 10]. Available from:

https://www.americananthro.org/ethics-and-methods

38. National Assembly of Vietnam. National Law on Forest Protection (Luật Bảo vệ và phát triển rừng, reference number: 58-LCT/HĐNN8) [Internet]. 1991 [cited 2021 Jun 14]. Available from:

https://thuvienphapluat.vn/van-ban/Tai-nguyen-Moi-truong/Luat-Bao-ve-va-phat-trien-rung-1991-58-LCTHDNN8-38067.aspx

39. National Assembly of Vietnam. National Law on Forest Protection (Luật Bảo vệ và Phát triển rừng, Reference number: 29/2004/QH11) [Internet]. 2004 [cited 2021 Jun 14]. Available from:

https://thuvienphapluat.vn/van-ban/Tai-nguyen-Moi-truong/Luat-Bao-ve-va-Phat-trien-rung-2004-29-2004QH11-52653.aspx

40. Gryseels C, Durnez L, Gerrets R, Uk S, Suon S, Set S, et al. Re-imagining malaria: Heterogeneity of human and mosquito behaviour in relation to residual malaria transmission in Cambodia. Malar J. 2015;14:1-12.

41. Peeters Grietens K, Gryseels C, Verschraegen G. Misdirection in the margins of malaria elimination methods. Crit Public Health [Internet]. Taylor \& Francis; 2019;29:390-400. Available from:

https://doi.org/10.1080/09581596.2019.1597965

42. Gryseels C, Bannister-Tyrrell M, Uk S, Set S, Suon S, Gerrets R, et al. A critical enquiry into variability of insecticidal net use in Cambodia: Implications for assessing appropriateness of malaria elimination interventions. Am J Trop Med Hyg. American Society of Tropical Medicine and Hygiene; 2019;100:1424-32. 43. Edwards HM, Chinh VD, Le Duy B, Thanh PV, Thang ND, Trang DM, et al. Characterising residual malaria transmission in forested areas with low coverage of core vector control in central Viet Nam. Parasites and Vectors [Internet]. BioMed Central Ltd.; 2019 [cited 2020 Oct 28];12:1-16. Available from:

https://parasitesandvectors.biomedcentral.com/articles/10.1186/s13071-019-3695-1

44. Edwards HM, Sriwichai P, Kirabittir K, Prachumsri J, Chavez IF, Hii J. Transmission risk beyond the village: entomological and human factors contributing to residual malaria transmission in an area approaching malaria elimination on the Thailand-Myanmar border. Malar J 2019181 [Internet]. BioMed Central; 2019 [cited 2021 Jul 29];18:1-20. Available from: https://malariajournal.biomedcentral.com/articles/10.1186/s12936-019-2852-5

45. Morel CM, Thang ND, Erhart A, Xa NX, Peeters Grietens K, Xuan Hung L, et al. Cost-Effectiveness of LongLasting Insecticide-Treated Hammocks in Preventing Malaria in South-Central Vietnam. PLoS One. 2013;8. 46. Sochantha T, Van Bortel W, Savonnaroth S, Marcotty T, Speybroeck N, Coosemans M. Personal protection by long-lasting insecticidal hammocks against the bites of forest malaria vectors. Trop Med Int Heal. 2010;15:336-41.

47. Thang ND, Erhart A, Speybroeck N, Xa NX, Thanh NN, Van Ky P, et al. Long-lasting insecticidal hammocks for controlling forest malaria: A community-based trial in a rural area of Central Vietnam. PLoS One. Public Library of Science; 2009;4.

48. Trung HD, Van Bortel W, Sochantha T, Keokenchanh K, Quang NT, Cong LD, et al. Malaria transmission and major malaria vectors in different geographical areas of Southeast Asia. Trop Med Int Heal [Internet].

John Wiley \& Sons, Ltd; 2004 [cited 2021 Apr 23];9:230-7. Available from:

http://doi.wiley.com/10.1046/j.1365-3156.2003.01179.x

49. Erhart A, Thang ND, Van Ky P, Tinh TT, Van Overmeir C, Speybroeck N, et al. Epidemiology of forest malaria in central Vietnam: A large scale cross-sectional survey. Malar. J. BioMed Central; 2005. p. 58. 50. Cui L, Yan G, Sattabongkot J, Cao Y, Chen B, Chen X, et al. Malaria in the Greater Mekong Subregion: Heterogeneity and complexity. Acta Trop. 2012; 
51. WHO, Searo, WHO Regional Office for South-East Asia. Malaria in the Greater Mekong Subregion: Regional and Country Profiles [Internet]. Delhi, India: WHO Regional office for South-East Asia; 2010. Available from: https://apps.who.int/iris/handle/10665/205432

52. Tusting LS, Ippolito MM, Willey BA, Kleinschmidt I, Dorsey G, Gosling RD, et al. The evidence for improving housing to reduce malaria: A systematic review and meta-analysis. Malar J [Internet]. ???; 2015 [cited 2020 Jun 10];14:209. Available from: ???

53. Tusting LS, Bottomley C, Gibson H, Kleinschmidt I, Tatem AJ, Lindsay SW, et al. Housing Improvements and Malaria Risk in Sub-Saharan Africa: A Multi-Country Analysis of Survey Data. von Seidlein L, editor. PLOS Med [Internet]. Public Library of Science; 2017 [cited 2021 Apr 24];14:e1002234. Available from: https://dx.plos.org/10.1371/journal.pmed.1002234

54. J KM, Carter R, Karunaweera ND. The role of improved housing and living environments in malaria control and elimination. Malar J [Internet]. BioMed Central; 2020;1-6. Available from:

https://doi.org/10.1186/s12936-020-03450-y

55. Rek JC, Alegana V, Arinaitwe E, Cameron E, Kamya MR, Katureebe A, et al. Rapid improvements to rural Ugandan housing and their association with malaria from intense to reduced transmission: a cohort study. Lancet Planet Heal. Elsevier B.V.; 2018;2:e83-94.

56. NIMPE. Annual Report on the National Malaria Control and Elimination Program 2018 (Internal Report). Hanoi; 2018.

57. Bannister-Tyrrell M, Xuan Xa N, Helena Kattenberg J, Van Van N, Khac Anh Dung V, Minh Hieu T, et al. Micro-epidemiology of malaria in an elimination setting in Central Vietnam. Malar J [Internet]. 2018 [cited 2020 Jun 11];17:119. Available from: https://doi.org/10.1186/s12936-018-2262-0

58. Duncan CR. Civilizing the Margins: Southeast Asian Government Policies for the Development of Minorities. Duncan CR, editor. Singapore: National University of Singapore Press; 2008.

59. Masunaga Y, Muela J, Nguyen TT, Tesfazghi K, Grietens KP. In Search of the Last Malaria Cases: Ethnographic Methods for Community and Private-sector Engagement in Malaria Elimination in Vietnam, Laos, and Cambodia (Under peer review). Malar J [Internet]. 2021 [cited 2021 Apr 15]; Available from: https://doi.org/10.21203/rs.3.rs-373228/v1

60. Kattenberg JH, Erhart A, Truong MH, Rovira-Vallbona E, Vu KAD, Nguyen THN, et al. Characterization of Plasmodium falciparum and Plasmodium vivax recent exposure in an area of significantly decreased transmission intensity in Central Vietnam. Malar J [Internet]. BioMed Central Ltd.; 2018 [cited 2020 Aug 27];17:1-17. Available from: https://link.springer.com/articles/10.1186/s12936-018-2326-1 61. Hii J, Rueda LM. Malaria vectors in the Greater Mekong Subregion: overview of malaria vectors and remaining challenges. Southeast Asian J Trop Med Public Health. 2013;44 Suppl 1.

62. Hii J, Vythilingam I, Roca-Feltrer A. Human and Simian Malaria in the Greater Mekong Subregion and Challenges for Elimination. Towar Malar Elimin - A Leap Forw [Internet]. InTech; 2018 [cited 2021 Feb 8]. Available from: http://dx.doi.org/10.5772/intechopen.76901

63. Grietens KP, Gryseels C, Dierickx S, Bannister-Tyrrell M, Trienekens S, Uk S, et al. Characterizing types of human mobility to inform differential and targeted malaria elimination strategies in Northeast Cambodia. Sci Rep. Nature Publishing Group; 2015;5:1-12. 
Figures

$100 \%(141 / 141)$ sleeping at home

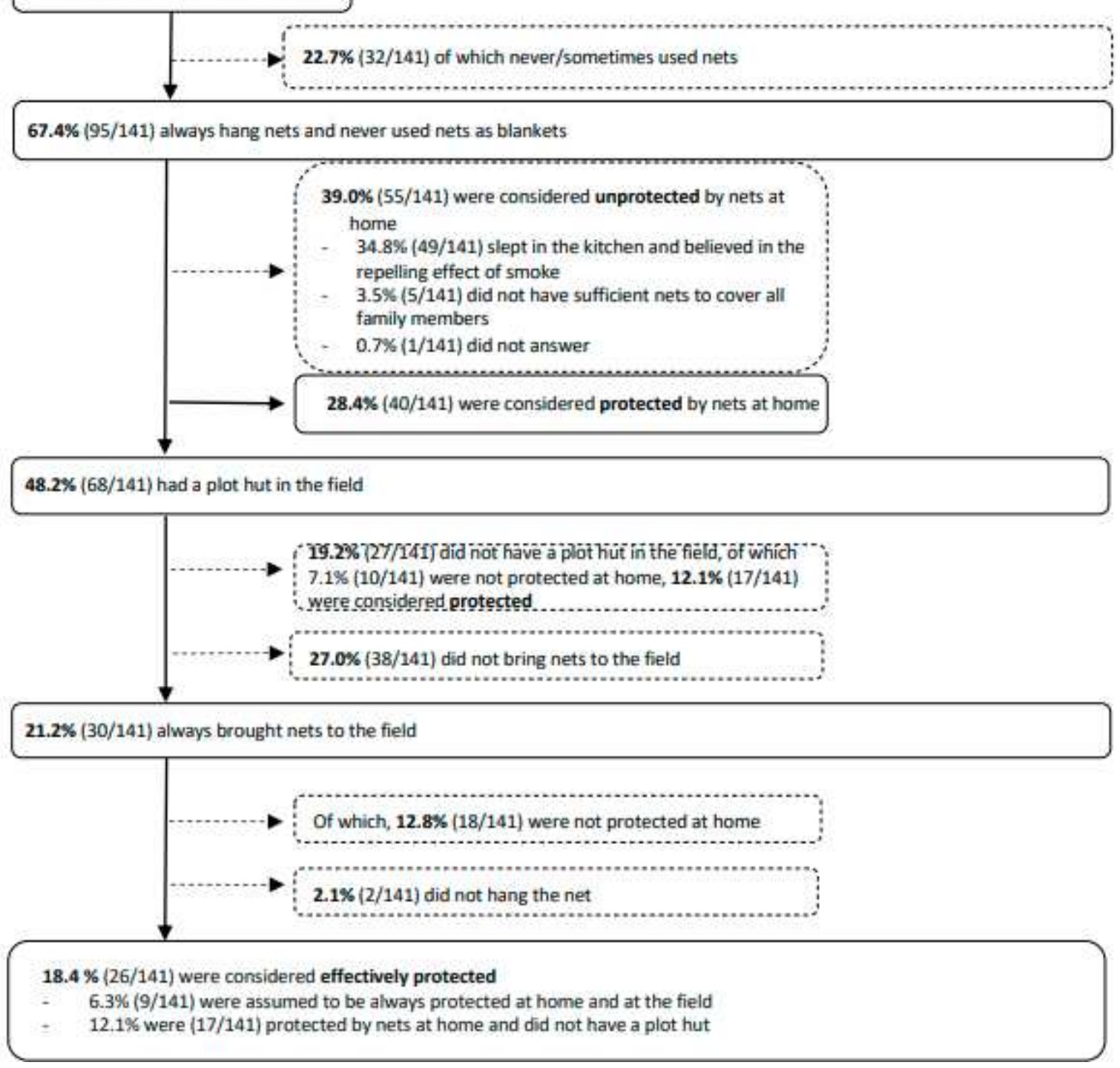

Figure 1

Consistent protection by bed nets at home and plot hut $(n=141)$ 

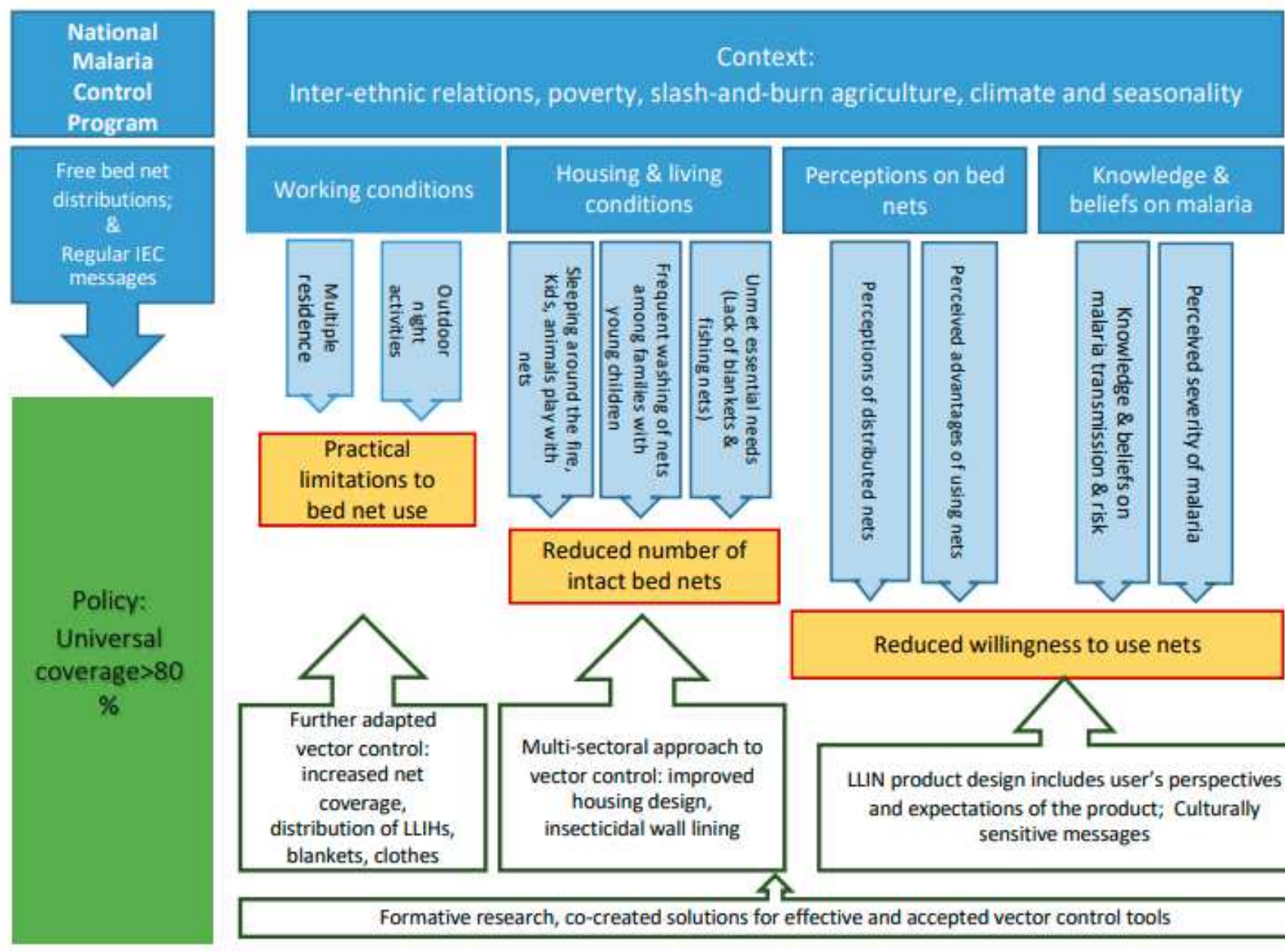

Knowledge \&
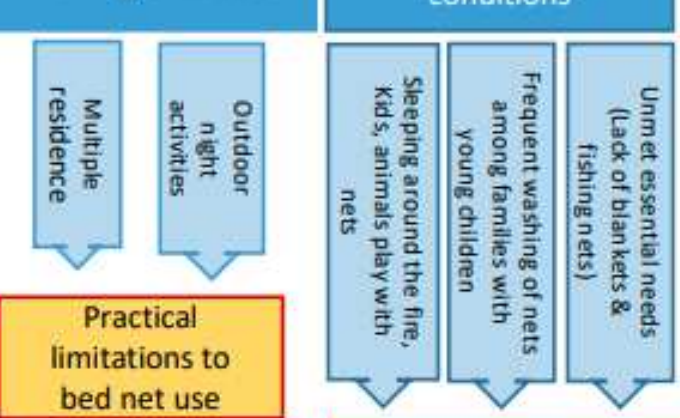

limitations to

bed net use

Reduced number of intact bed nets
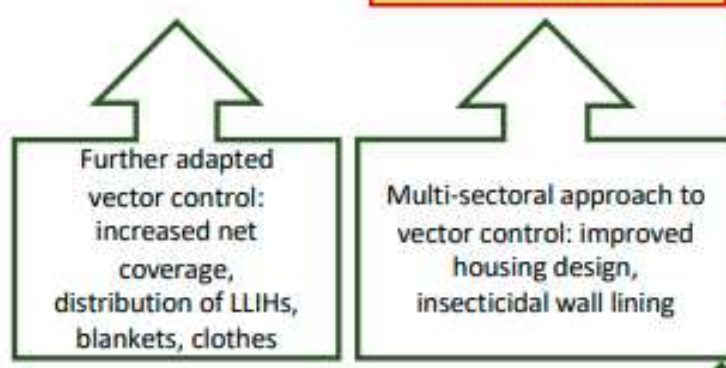

Multi-sectoral approach to vector control: improved housing design, insecticidal wall lining

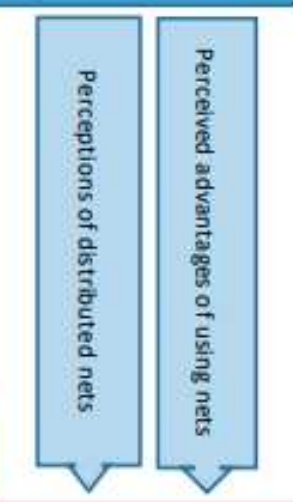

beliefs on malaria
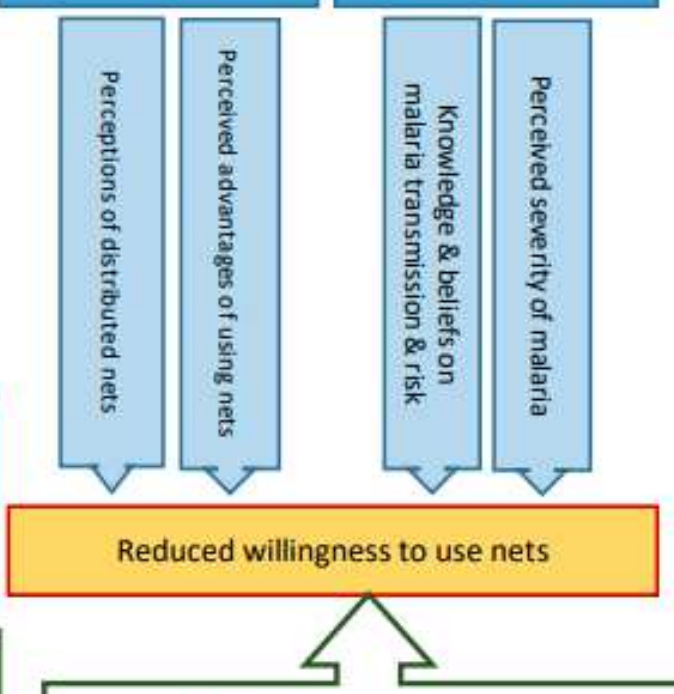

LLIN product design includes user's perspectives and expectations of the product; Culturally sensitive messages

Formative research, co-created solutions for effective and accepted vector control tools

\section{Figure 2}

Intervention model to address contextual factors influencing bednet use

\section{Supplementary Files}

This is a list of supplementary files associated with this preprint. Click to download.

- TableWhyusingbednetsisachallengeincentralVietnam.pdf

- Image1.png 